\title{
Interactive comment on "Impacts of atmospheric transport and biomass burning on the interannual variation in black carbon aerosols over the Tibetan Plateau" by Han Han et al.
}

Han Han et al.

hhannju@163.com

Received and published: 2 September 2020

The comment was uploaded in the form of a supplement:

https://acp.copernicus.org/preprints/acp-2020-299/acp-2020-299-AC1-supplement.pdf

Interactive comment on Atmos. Chem. Phys. Discuss., https://doi.org/10.5194/acp-2020-299, 2020. 